\title{
Clopidogrel-induced Pill Oesophagitis
}

\author{
James C Blankenship ${ }^{1}$ and Matthew J Shellenberger ${ }^{2}$ \\ 1. Department of Cardiology, Geisinger Medical Center, Danville, PA, USA; 2. Department of Gastroenterology, Geisinger Medical Center, \\ Danville, PA, USA
}

\section{Keywords}

Oesophagitis, coronary stenting, clopidogrel

Disclosures: James C Blankenship and Matthew J Shellenberger have no financial or non-financial relationships or activities to declare in relation to this article.

Review Process: Double-blind peer review.

Compliance with Ethics: Informed consent was received from the patient involved in this case study.

Authorship: The named authors meet the International Committee of Medical Journal Editors (ICMJE) criteria

for authorship of this manuscript, take responsibility for the integrity of the work as a whole, and have given final approval for the version to be published.

Access: This article is freely accessible at touchCARDIO.com (c) Touch Medical Media 2020.

Received: 17 March 2020

Accepted: 12 May 2020

Published Online: 14 July 2020

Citation: Heart International. 2020;14(1):56-8

Corresponding Author: James C Blankenship,

Geisinger Medical Center, 100 N Academy Ave, Danville, PA 17822, USA. E: jblankenship@geisinger.edu

Support: No funding was received in the publication of this article.
Antiplatelet agents are routinely given to prevent thrombosis of coronary stents. ${ }^{1}$ When antiplatelet drugs are not given before percutaneous coronary intervention $(\mathrm{PCl})$, they may be given on the table during PCl. Ingestion of pills while supine on the catheterisation table often causes mild dysphagia and discomfort but, rarely, it can cause a more serious event. We report a case of pill oesophagitis following supine clopidogrel tablet ingestion, likely due to clopidogrel lodging in the oesophagus during a coronary stenting procedure.

\section{Case history}

A 78-year-old female presented for elective cardiac catheterisation for class II angina. She was symptomatic despite using isosorbide mononitrate $30 \mathrm{mg}$ daily and metoprolol tartrate $50 \mathrm{mg}$ twice daily. Cardiac catheterisation showed $80 \%$ stenosis in the mid-left anterior descending coronary artery (Figure 1). Ad hoc PCl with a drug-eluting stent $\left(2.5 \times 12.0 \mathrm{~mm}\right.$ Xience $\mathrm{V}^{\circledR}$ stent, Abbott Vascular, Santa Clara, CA, USA) was performed (Figure 2). Clopidogrel (six 75 mg tablets) was administered on the table after diagnostic imaging and before $\mathrm{PCl}$. After $\mathrm{PCl}$ the patient reported discomfort deep in her throat, which started when clopidogrel was ingested and persisted for several hours. This discomfort was separate to her baseline angina and the electrocardiogram was normal, so her symptoms were attributed to difficulty swallowing the clopidogrel tablets. Her discomfort resolved and she was discharged later the same day in a good condition.

Routine telephone follow-up was conducted the next day. The patient reported that she had solid-food dysphagia and non-exertional chest discomfort, which was different compared with her previous angina. Upper gastrointestinal endoscopy 1 day later showed two ulcers with no evidence of luminal narrowing or stricture in the middle third of the oesophagus (Figure $3 A-D$ ), consistent with pill oesophagitis. She was treated with omeprazole $20 \mathrm{mg}$ twice daily and sucralfate suspension $1 \mathrm{~g}$, by mouth, four times a day, for 8 weeks. Her symptoms resolved over the next few days and repeat endoscopy 8 weeks later showed healing of the oesophageal ulcers (Figure 3E).

\section{Discussion}

We believe this is the first reported case of pill oesophagitis attributable to a thienopyridine drug, or any drug given during PCl. We attribute the patient's oesophagitis to ingestion of six clopidogrel tablets while lying supine on the catheterisation laboratory table and hypothesise that at least one tablet lodged in her mid-oesophagitis. This is supported by the fact that she noticed discomfort deep in her throat that persisted several hours after ingesting the clopidogrel tablets. The linear ulcerations found on endoscopy were felt by the endoscopist to be typical of pill oesophagitis.

Other possible causes of her oesophagitis seem less likely. She was taking aspirin 81 mg daily, but reported no oesophageal symptoms on visits over several years prior to catheterisation. She received $324 \mathrm{mg}$ of aspirin on the morning of catheterisation, sitting upright and taken with water, but had no trouble ingesting this. Endoscopy 8 weeks later showed complete resolution of oesophagitis despite continuing aspirin $81 \mathrm{mg}$ per day and clopidogrel $75 \mathrm{mg}$ per day. On subsequent visits to her cardiology and pulmonary physicians, she reported no further chest pains or oesophageal symptoms. However, despite these points, we cannot completely exclude other causes. 
Figure 1: Shallow right anterior oblique image of left anterior descending coronary artery with an $80 \%$ stenosis at the origin of a large septal perforator

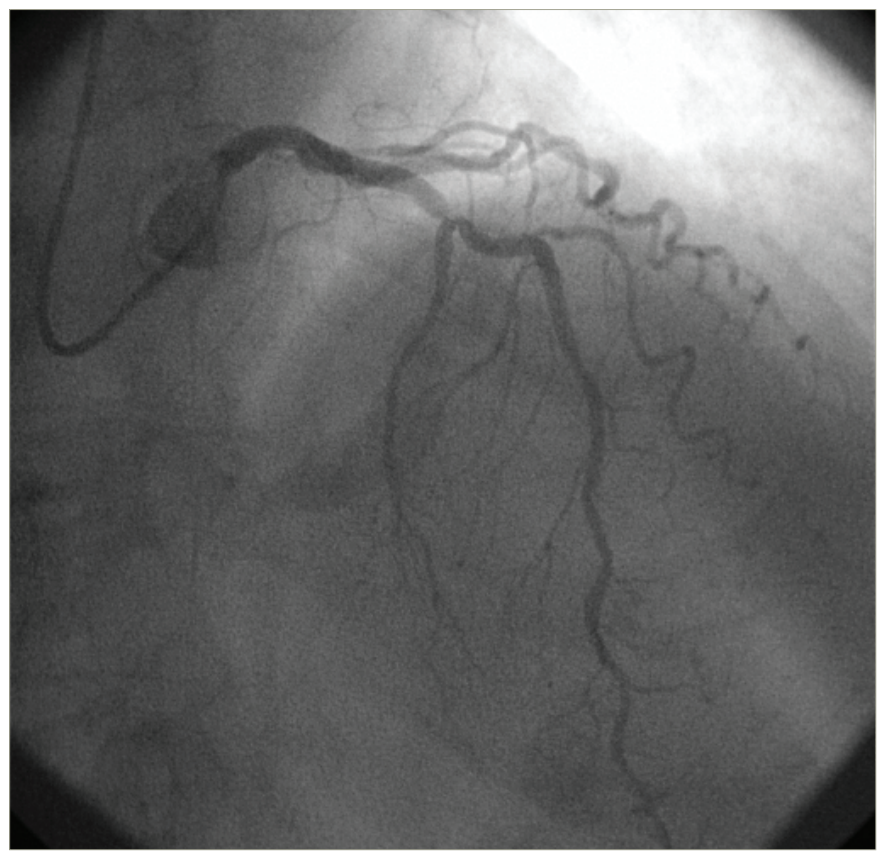

Figure 2: Right anterior oblique view of left anterior descending coronary artery with the lesion reduced to $0 \%$ by stenting

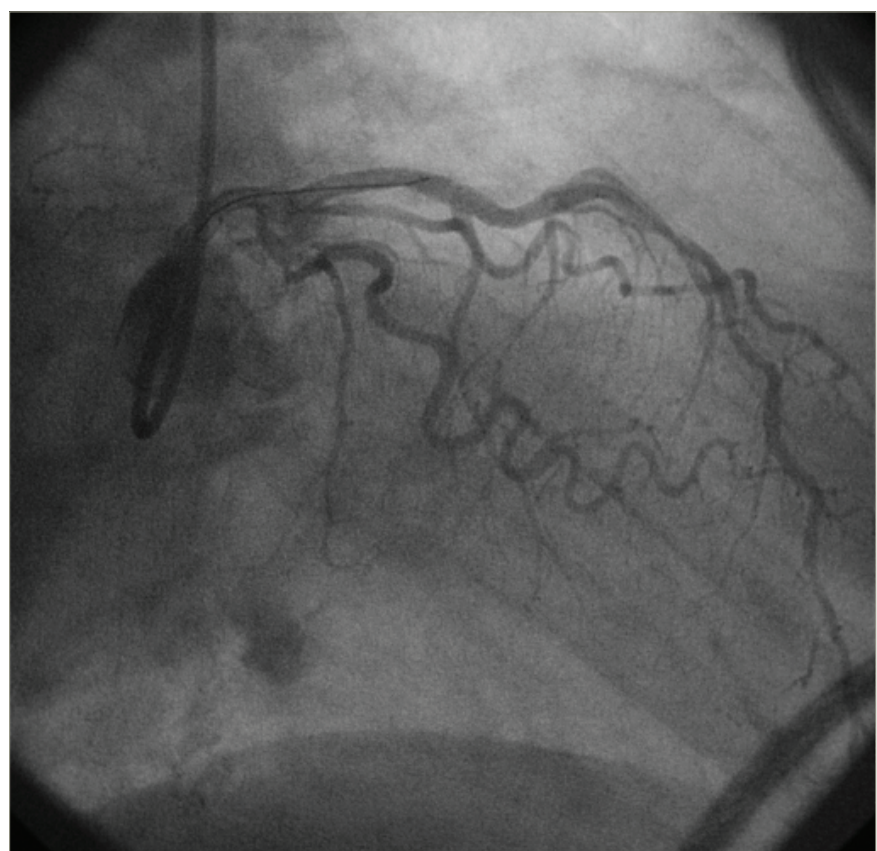

The proximal end of the stent is located at the distal tip of the radiodense guidewire.

Difficulty ingesting pills is very common, and can lead to pills lodging in the oesophagus, which has been reported with doxycycline, anti-inflammatory drugs, potassium chloride and bisphosphonates. ${ }^{2-4}$ It is usually self-limited but, rarely, it can lead to haemorrhage, stricture, perforation and mediastinitis. ${ }^{4}$ The characteristics of the culprit medication can predispose to oesophageal injury, including its chemical constitution, the size and the coatings of the pill and contact time with the mucosa, which can be influenced by oesophageal motility

Figure 3: Upper gastrointestinal endoscopy 2 days and 8 weeks after clopidogrel ingestion
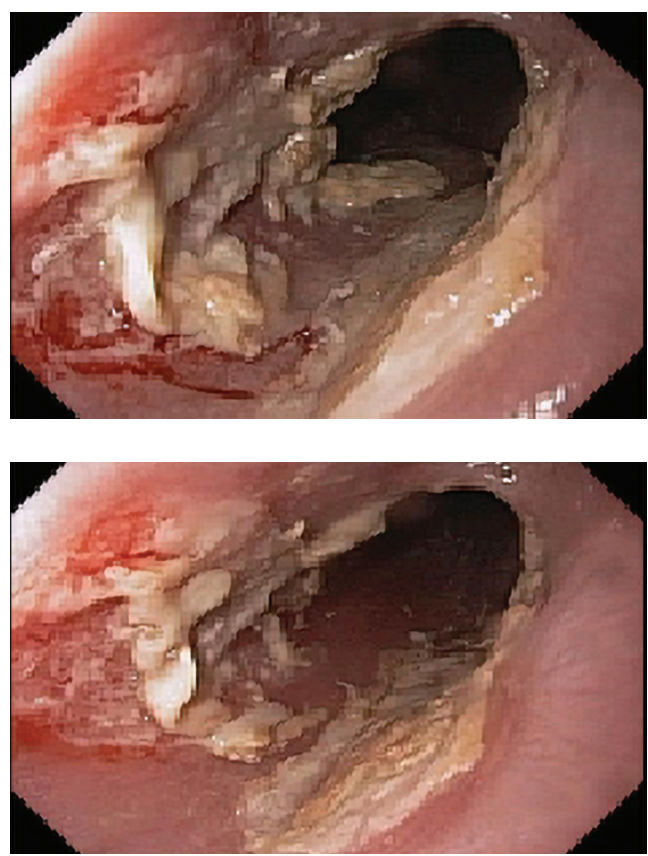

C

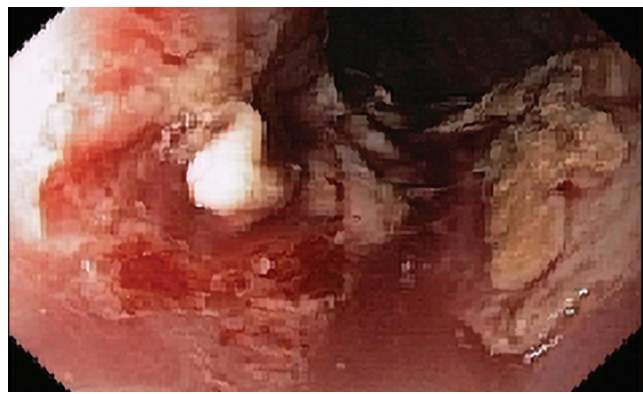

D
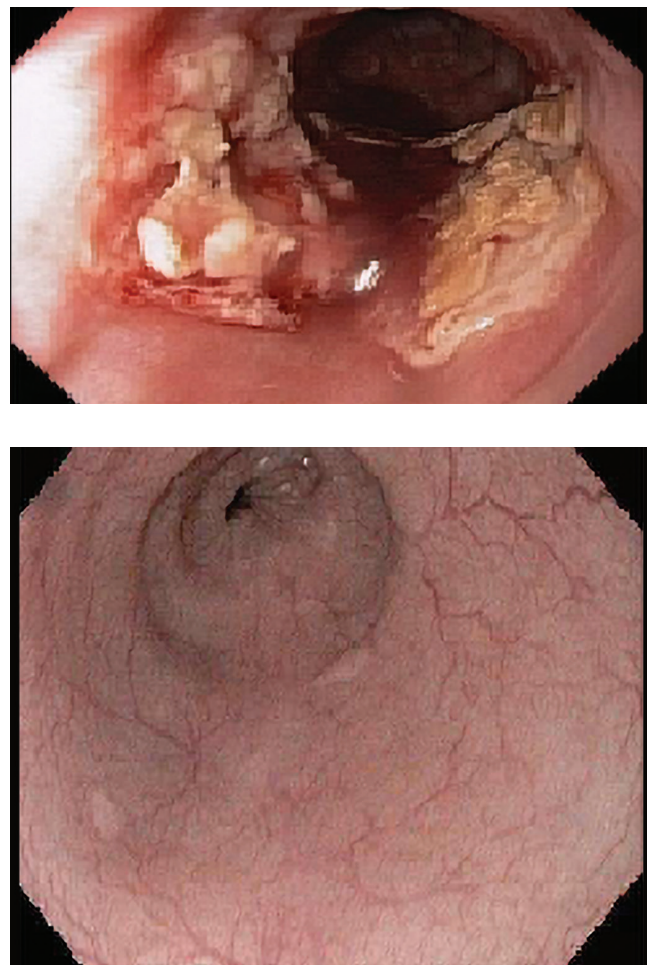

A-D: Upper gastrointestinal endoscopy showed two ulcers with no evidence of luminal narrowing or stricture seen in the middle third of the oesophagus. E: Repeat endoscopy after 8 weeks with healed oesophageal ulcers. 
abnormality, left atrial enlargement, recumbent position and inadequate amounts of fluid. ${ }^{4}$ While proton-pump inhibitors do not prevent oesophageal erosions associated with antiplatelet agents, ${ }^{5}$ they are commonly used to treat pill oesophagitis. ${ }^{6}$

Pill oesophagitis might be responsible for some of the upper gastrointestinal discomfort or pill intolerance that affect clopidogrel adherence. ${ }^{7.8}$ If the pill remains in the oesophagus for a prolonged interval or absorption is incomplete, this might delay the achievement of therapeutic serum levels of the medication, and increase the risk of stent thrombosis. Patients undergoing elective $\mathrm{PCl}$ are often discharged on the day of the procedure, and symptoms of pill oesophagitis may develop only after discharge and be reported to their primary care physicians, who may not be aware of the risk of this entity. Finally, symptoms of pill oesophagitis may be easily confused with recurrent angina or ischaemia after $\mathrm{PCl}$, so awareness of this entity may help physicians avoid referral for unneeded hospitalisations or repeat catheterisations.

Ideally, patients would be loaded with P2Y12 receptor inhibitors before undergoing diagnostic procedures that lead to $\mathrm{PCl}$. However, since pre-loading may delay bypass surgery if severe multi-vessel disease is identified, often pre-loading is not performed and patients are given antiplatelet drugs on the table. In these cases, adequate ingestion should be ensured. It is prudent to ask about oesophageal motility disorders or symptoms of dysphagia before asking patients to ingest medications when supine. Adequate water should be given to flush the medications through the oesophagus. It may be possible to raise the patient's head and torso slightly off the table to aid swallowing, particularly if radial access is used, since an upright position decreases the risk of medications lodging in the oesophagus. $\left.{ }^{3}\right]$

1. Levine GL, Bates ER, Blankenship JC, et al. 2011 ACCF/AHA/SCAl Guideline for Percutaneous Coronary Intervention: a report of the American College of Cardiology Foundation/American Heart Association Task Force on Practice Guidelines and the Society for Cardiovascular Angiography and Interventions. Circulation. 2011;124:e574-651.

Fields 1 Co JT Schulze KS Pill properties that cause dysphagia and treatment failure Curr Ther Res Clin Exp 2015:77:79-82.

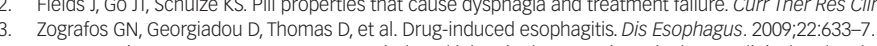

3. Zografos GN, Georgiadou D, Thomas D, et al. Drug-induced esophagitis. Dis Esophagus. 2009;22:633-7.

Pusztaszeri MP, Genta RM, Cryer BL. Drug-induced injury in the gastrointestinal tract: clinical and pathologic considerations. Nat Cin $P$.
Sugimoto M, Uotani T, Nishino M, et al. Antiplatelet drugs are a risk factor for esophageal mucosal injury. Digestion. 2013;87:281-9.

Panarelli NC. Other forms of esophagitis: it is not gastroesophageal reflux disease, so now what do I do? Surg Path Clin. 2017:10:765-79.

CAPRIE Steering Committee. A randomised, blinded, trial of clopidogrel versus aspirin in patients at risk of ischaemic events (CAPRIE). Lancet. 1996;348:1329-39.

8. Poh CL, Chan MY, Lau C, et al. Prevalence and predictors of premature discontinuation of dual antiplatelet therapy after drug-eluting stent implantation: importance of social factors in Asian patients Intern Med J. 2011;41:623-9. 